\title{
Atividade Fisica: acontecimento do acaso ou necessidade de sobrevivência
}

\author{
*Wilson do Carmo Júnior
}

Essa é uma abordagem filosófica sobre o discurso da Educação Física na busca de um referencial legítimo da sua identidade cultural e da sua perspectiva quanto ao sujeito corporal que está inserido nessa identidade.

Refiro-me às questões pelas quais podemos interpretar o sentido da Educação Física como uma entidade da cultura, como também fazer referências científico-filosóficas, artístico-religiosas da sua antropologia. Acredito ser possível sustentar os conceitos de uma Educação Física mais pura, inerentes aos elementos que caracterizam a presença humana como sujeito de estudo. Abordar a Educação Física como entidade, não como disciplina, pode ter sustentação cultural rigorosa, pois traz, dentro do seu sistema, a presença de dois elementos fundamentais para a compreensão do homem na sua totalidade: o corpo e o movimento.

Não se trata de referências ao corpo humano como organismo ou produtor da ação mecânica. Trata-se de uma compreensão da sua ontologia e do efeito cultural provocado pelo uso da relação corpo-movimento como primeiro instrumento de si mesmo no sentido da sobrevivência e perpetuação da espécie. Naturalmente que esse discurso é pretensioso e polêmico e que exige uma reinterpretação do processo pelo qual o ser humano percebeuse necessitado de fazer uso das habilidades motoras para integrar-se como parte do mundo natural. Contudo, estamos dispostos a compreender a Educação Física como uma práti$c a$ de ação-movimentação correspondente a uma experiência cultural inusitada e evidente. Podemos requerer o espectro ontológico dessa ação-movimentação como necessidade lógica amplamente prestigiada desde o universo cosmogônio.

Parece ser necessária uma busca antropológica sobre o uso do corpo e do movimento humano como atividade cultural além da atividade fisica, sobretudo porque há conceitos e fenômenos naturais que se integram como problema humano existencial. Esse efeito não se resume numa problemática do culto à saúde como contraposição à doença ou ao sedentarismo. Há um corpo cultural e há um corpoorganismo, há uma motricidade inerente ao corpo humano humano cultural. Assim como há uma motricidade preconcebida pela natureza humana, quando esta se localizava e existia como projeção do mundo vivido.

Talvez seja o caso de reaproximar o corpo-motricidade como estatuto da Educação Física primordial, pois essa relação descreve questões humanas primordiais e de pres- 
Parece ser necessário uma

busca

antropológica

sobre o uso do

corpo e do

movimento

humano como

atividade

cultural além da

atividade física,

sobretudo

porque há

conceitos $e$

fenômenos

naturais que se

integram como

problema

humano

existencial. tígio: o ser homem como ser corpo ${ }^{1}$. Estou tentando afirmar que há uma possibilidade de responsabilizar a Educação Física por questões humanas fundamentais, além da ordem estrutural disciplinar, acadêmica e profissional que a caracteriza. Há possibilidades de redescobrir uma prática fundamental, a prática da existência cultural no sentido polissêmico da palavra.

Portanto, a Educação Física parece estar presente na cultura, é cultura, e sua representação está sustentada por uma dinâmica científico-filosófica, artístico-religiosa. A primeira representação se manifesta na Physis, a relação estreita homem-natureza; a segunda representação localiza-se no Ethos, a relação intuitiva da fé e da intenção de estar no mundo.

Não parece ser novidade, e talvez seja de conhecimento disponível, que a experiência humana transitou os séculos sob duas formas de pensamento: mágico-religioso lógicoformal. Estamos sentados num banco cultural sustentado pelo pensamento lógico em detrimento de um pensamento mágico. Somos governados pela razão, a cosmologia em detrimento da cosmogonia.

Entretanto, nossas virtudes mais primitivas ainda borbulham nas formas mais elementares do cotidiano, retidas no inconsciente individual e coletivo. Essas virtudes não são passíveis de lógica formal exclusiva. Alguns desses conhecimentos não são científicos ou filosóficos. E assim que posso compreender que há outras categorias de pensamentos a serem pesquisadas. Talvez tenha sido essa a primeira preocupação grega: buscar o desconhecido com fundamento humano, ou seja, verificar que as coisas sensíveis podem ser inteligíveis, que as coisas do mundo natural objetivo sofrem transformações por serem humanas e, algumas vezes, inexplicáveis.

Procedimentos acerca do rendimento humano como busca de ascensão, do sentido da prática como intencionalidade e intervenção, da consciência como signficação e expressão demonstram que o homem no mundo é eminentemente prático. Esse princípio, dotado de leis naturais, responsabiliza a Educação Física para determinar a capacidade humana de agir como quem necessita da ação para sobreviver. $\mathrm{O}$ ajuste corporal-e-motor, intencio- nal, reflete o instinto de vida. Fomos e somos dotados dessa cultura motora inata que antecede o esforço físico plastificado. As técnicas $e$ as práticas corporais dão-nos indícios de uma aprendizagem motora primordial ${ }^{2}$.

Podemos afirmar uma Educação Física com um nexo social evidente, um corpo e um movimento humano estruturado ontologicamente, um fluxo imanente que reconduz o ser humano às suas origens e o faz redescobrir enquanto ser: o homem caçador e ator. A conjunção mítico-lógica do corpo com o movimento, que são temas que podem ser chamados ontologicamente de ginástica, caso seja possível redescobrir sua prática como cultura, e por que não dizer um fenômeno natural ou a primeira Educação Física.

Agir, sentir e pensar fazem parte da natureza ou são a natureza. Podemos acreditar que o homem primitivo sabia, de certa forma, como explicar esses princípios: pela linguagem e pelo mito ${ }^{3}$. O homem civilizado parece ter se distanciado deles. Temos aí uma tricotomia teológica e uma tricotomia antropológica, uma pré-ocupação cultural que necessita ser vivida antes de ser experimentada, uma questão de referência.

Quando temos o atrevimento de propor um estudo, um conhecimento, um saber para a Educação Física, esta não escapa desse emaranhado de problemas. E é isso que estamos vivendo. Contudo, é preciso acreditar que há lógicas e mágicas nos conceitos, nos símbolos e nas linguagens.

Sabemos, entretanto, que o uso do corpo e do movimento humano no mundo primitivo fez-se por necessidade e não pelo acaso. A sobrevivência foi a primeira necessidade humana por princípio elementar, depois surgiu a consciência manisfestada em ato e potência, seguindo o ritmo da vida em que o corpo e todo processo de aprendizagem preexistiu pelo uso do corpo como instrumento. Há uma espécie de atletismo primitivo quando nos referimos às práticas e técnicas corporais das tribos arcaicas, talvez a Educação Física primordial. Daí a referência que corpo e movimento são elementos da cultura. Há uma natureza do corpo e do movimento, como também é possível haver uma consciência natural quando se trata de buscar o referencial através do 
qual tentamos justificar um conceito de corpo e de movimento. Devemos recorrer a outras linguagens para poder compreender melhor o fenômeno. Assim como todo conteúdo humano podemos ampliar em humanidade, o conteúdo do corpo podemos ampliar em corporeidade, conseqüentemente o ato motor em motricidade. Essa relação nos fez compreender que toda atividade manifesta-se como consciência ${ }^{4}$. Há tanto filosofia quanto ciência, arte ou mesmo religião nessas metáforas. E por que não responsabilizar a Educação Física para sustentar esse conteúdo semântico?

Já descobrimos que a natureza do corpo não é a mesma coisa que o conceito de corpo, assim há uma motricidade que não se explica, como a primeira intenção no movimento. A ciência talvez venha a explicar esse fenômeno, porém é preciso conceituálo e deixá-lo aberto à subjetividade do ato de mover, assim talvez aprenderemos a observá-lo com profundidade intencional, profundidade esta que talvez seja redescoberta da Educação Física como encontro fundamental da objetividade-subjetividade inerente às questões humanas, em que o homem será o principal ator-sujeito-mediador da relação corpo-movimento.

Algumas respostas da relação corpomovimento são de caráter interdisciplinar; não é privilégio da Educação Física. E preciso e necessário captar o efeito dessa relação íntima antes mesmo de tentar mudar o nome da entidade que a estuda. E necessário com-ciência rigorosa na interpretação das coisas antes de tentar fugir dos limites éticos de referência e competência. É preciso inspiração estética, consciência moral e ambiente ético na mesma intensidade da transpiração e adapatação.

Assim estaremos diante de um fenômeno inusitado para a Educação Física, em que sua representação e sua máxima seriam a compreensão antropológica do conjunto de modalidades de significação e expressão que se manifestam no mundo contemporâneo. Estaremos redescobrindo o sentido mais legítimo da ginástica, da dança, do lúdico, do esporte. Somente a Educação Física e nela é possível elaborar uma estrutu- ra cultural de tal ordem em que surja uma resposta sobre a prática autêntica e inequívoca: corpo-em-movimento. Temos aí a linguagem do movimento, a pré-posição de uma prática seguida de outra.

Há muita antropologia filosófica antes do processo ensino-aprendizagem, há muito conhecimento encoberto e subjetivo que nos indica que a explicação concreta $\mathrm{e}$ objetiva não é a única. Uma situação, para ser legítima, exige a outra. A explicação primária do ato de aprender é por excelência inexplicável, uma função jamais aceita pela objetividade dos comportamentos. Entretanto, a subjetividade dos comportamentos é humana e dela jamais poderemos deixar de fazer uso.

Talvez estejamos procurando o sujeito e não o objeto de estudo, e talvez por equívoco conceituai ainda não o encontramos. Mas ele está aí, bem perto, basta ver o universo infantil, longe da psicopedagogia artificial; basta ver o jogo como princípio do vaivém lúdico que inspira beleza e brincadeira nas relações humanas puras ${ }^{5}$.

Temos o recurso simbólico da evolução das coisas humanas vistas por outras percepções e linguagens, outros pontos de referências. Na realidade, estamos redescobrindo uma prática intencional evidente, destituindo o equívoco e a crença em que a prática da atividade física é um espetáculo alegórico de sublimação. Estamos desfazendo gradativamente o ridículo cálculo contemporâneo do corpo sustentado por padrões e modelos, a conveniência modista da ditadura do marketing, que atropela a auto-estima e desconjura o efeito legítimo da transpiração. Devemos acreditar, contudo, que a Educação Física já responde por uma cultura corporal como sendo humana e existencial, que simboliza e eterniza a ação humana como princípio da sobrevivência.

Há um homem presente na Educação Física que buscamos; o preexistente que é total, prático, necessita de rendimento e não é absoluto. Há um homem em movimento no mundo natural esperando que alguma área do conhecimento o descubra. Que seja a Educação Física.
Podemos afirmar uma Educação Física com um nexo social evidente, um corpo e um movimento

humano

estruturado ontologicamente, um fluxo imanente que reconduz o ser humano às suas origens e of faz redescobrir enquanto ser: o homem caçador $e$ ator. 


\section{REFERÊNCIAS BIBLIOGRÁFICAS}

BUYTENDIJK, F.J.J. O jogo humano. In: Nova Antropologia: o homem na sua existência biológica, social e cultural. São Paulo: Vol. 4, p. 63-78, 1977.

CASSIRER, E. Linguagem Mito. Lisboa, Editora Rés, 1976.

MARCEL, G. If I am my body. In: Philosophic inquiry in sport. Champaign Illinois, Human Kinetics, 1988.

MAUSS, M. Sociologia e Antropologia. São
Paulo, Editora da USP, Vol. II, 1974.

MERLEAU-PONTY, M. L'oeuil et l'Esprit. Paris, Editions Gallimard, 1963.

\section{UNITERMOS}

Filosofia do corpo, Educação Física e corporeidade, antropologia do movimento humano.

* Wilson do Carmo Júnior é professor do Departamento de Educação Física do Instituto de Biociências da UNESP - Rio Claro/SP. 